\title{
Los caminos del bien y del mal en la pintura novohispana, siglo XVIII
}

Gisela von Wobeser

Universidad Nacional Autónoma de México ${ }^{1}$

La Iglesia católica plantea la existencia de dos caminos que los fieles pueden recorrer de acuerdo al libre albedrío que Dios les otorgó: el del bien, que conduce al cielo, y el del mal, que lleva al infierno. Estos caminos aluden simbólicamente al comportamiento que los fieles tienen en vida, mismo que será juzgado por Dios después de la muerte. Los hombres que han actuado de manera correcta y se han apegado a las directrices establecidas por la Iglesia obtendrán la bienaventuranza y podrán gozar eternamente de las delicias del cielo, mientras los que hayan tenido un comportamiento inadecuado deberán sufrir eternamente las penas del infierno.

Dado que la Iglesia siempre se ha apoyado en imágenes para transmitir sus creencias, la finalidad del presente artículo es analizar la manera en que tres pintores novohispanos del siglo XVIII han plasmado estas ideas en sus lienzos. Se trata de pinturas al óleo, de formato mediano, que se encuentran en buen estado de conservación (salvo uno de ellos que está mutilado del lado derecho) y tienen carteles que ayudan a esclarecer su significado.

El primero de ellos es La caridad perfecta de Jesucristo soberano redentor del mundo de Antonio Sánchez, fechado en 1757, que pertenece a una

\footnotetext{
${ }^{1}$ Instituto de Investigaciones Históricas.
} 
colección particular. ${ }^{2}$ Su título alude al tema central de la obra que representa a Jesucristo como redentor del mundo, con el torso desnudo, túnica y manto rojos, sangrando de sus costados, entronizado sobre una fuente de dos cuerpos, que recoge su sangre. Varias personas rodean la fuente y enjuagan sus corazones en la sangre purificadora. La escena es presidida en la parte superior por Dios Padre y por el Espíritu Santo. Al centro, en la parte inferior de la pintura aparece un niño, posiblemente un retrato como infante del concomitante Joseph Cleto Montaño o de su hijo, quien se beneficia del poder redentor de Jesús al encontrarse inmediatamente debajo de éste y junto a la fuente. Hacia la derecha e izquierda de Jesucristo (izquierda y derecha del espectador) se erigen los caminos del bien y del mal, que conducen respectivamente hacia el cielo y el infierno, pintados simétricamente en alusión al paralelismo antagónico que caracteriza a estos dos lugares ${ }^{3}$ [fig. 1].

La segunda pintura Los peligros del alma es anónima y forma parte de la colección de la Pinacoteca de la Profesa (Ciudad de México). Asimismo, está dividida verticalmente en dos secciones: del lado derecho aparece el camino que conduce al cielo y del izquierdo, el que lleva al infierno. Aunque esta obra no está fechada, la técnica empleada así como los trajes que portan los personajes permiten situarla en el siglo XVIII. Lamentablemente, la falta de la sección derecha de la obra, debida a la mencionada mutilación, implica que el camino del bien esté incompleto [fig. 2].

La tercera obra, Rey de Jerusalén y rey de Jericó (conocida comúnmente como Cristo descendiendo al infierno $)^{4}$, se ha atribuido a Francisco Jerónimo Zendejas y forma parte de la colección del Museo Nacional de Historia de la Ciudad de México. Como las anteriores, está dividida en dos secciones verticales, la de la izquierda, dedicada al camino del bien y la de la derecha, al del mal. El primero conduce al cielo, representado como Jerusalén celestial y de la cual se ven la barda y la puerta de acceso, adornadas con piedras preciosas, así como un sol resplandeciente que la inunda $\mathrm{a}^{5}$ el segundo, al infierno, caracterizado mediante nubes espesas y oscuras y llamas en tonos rojos y amarillos, así como mediante la presencia de dos Demonios de grandes proporciones [fig. 3].

2 Óleo sobre tela, que mide 105 por $164 \mathrm{~cm}$. Esta pintura ha sido descrita someramente por Gustavo Curiel y Antonio Rubial en: CuRIel y Rubial 1999: 85.

3 El camino del bien es denominado "escala de virtud" en las inscripciones de la parte inferior.

${ }^{4}$ La sustitución del título Cristo descendiendo al infierno por el de Rey de Jerusalén y rey de Jericó, se hace con base en la temática que aborda y las inscripciones localizadas al pie de la pintura. Agradezco a Abraham Villavicencio sus útiles comentarios para hacer dicha reinterpretación.

5 Este tipo de representación del cielo proviene de la Jerusalén celestial, descrita por san Juan en el Apocalipsis. Von WobeSER (en prensa). 


\section{ANTECEDENTES}

La idea de la existencia de dos caminos simbólicos que conducen respectivamente al cielo y al infierno, fue introducida a Nueva España en el siglo XVI por los frailes evangelizadores. Ellos solían valerse de láminas para facilitar la trasmisión a los indígenas de las bases doctrinales de la nueva religión. ${ }^{6}$ Desafortunadamente no se conservaron estas láminas, pero contamos con una descripción, por parte del cronista Juan Bautista Méndez, de la que usaba el franciscano fray Gonzalo Lucero para ejemplificar el concepto de los dos caminos. Dice que en ella estaban representadas dos canoas navegando en el mar; una de las cuales se encaminaba hacia el cielo, situado en la parte superior del lienzo y la otra, hacia el abismo, donde se encontraba el infierno. En la primera canoa iban indios e indias "con sus rosarios en las manos y al cuello, unos tomando disciplinas y otros, puestas las manos, orando". Esta canoa iba acompañada de ángeles "que llevaban remos en las manos y los daban a los indios para que remasen en demanda de la gloria". Varios demonios estaban asidos a la barca tratando de impedir que prosiguiera su ruta, pero eran combatidos por los indios de la canoa y por los ángeles con "las armas del santo rosario". En la canoa que se dirigía hacia el infierno iban indios e indias comportándose mal. Unos se embriagaban "con grandes vasos de vino... que los demonios ofrecían a unos y las mujeres que presentes estaban a otros", otros reñían y se quitaban la vida y algunos hombres y mujeres estaban entregados a los placeres sensuales, "se daban las manos y brazos". Había ángeles sobrevolando esta canoa tratando de llamar la atención de los ocupantes, pero éstos "iban tan atentos y cabizbajos a sus entretenimientos, que dejaban por espaldas las inspiraciones que los ángeles traían de parte de Dios, dándoles rosarios". Los demonios que remaban en esta canoa iban "con grande contento y porfiadas fuerzas, significando sus ansias por llegar al desventurado puerto del infierno", representado en la parte inferior del lienzo."

Otro ejemplo temprano de la representación gráfica de los dos caminos lo tenemos en el grabado número 20 que lleva por título "Representación del pecador", perteneciente a la Retórica cristiana de Diego Valadés. ${ }^{8}$ En este grabado, al parecer hecho por el propio autor, ${ }^{9}$ aparece del lado izquierdo el camino

${ }^{6}$ Los frailes recurrieron a imágenes para transmitir la doctrina católica a los indios "... puesto que las cosas que se ven mueven con más potencia las fuerzas del hombre”, VALADÉs 1989: 485.

7 MÉndez 1993: 308.

${ }^{8}$ Diego Valadés se refiere ampliamente al uso de imágenes para la catequización de los indios en la Retórica cristiana.

9 Diego Valadés había estudiado pintura en el Colegio de Santa Cruz de Tlatelolco, fundado por fray Pedro de Gante. Véase introducción de Esteban J. Palomera, en: VALADÉs 1989: XIII. 
del bien, simbolizado mediante un ángel que porta una larga vara que termina en un crucifijo y tiene siete cartelas con los nombres de virtudes: humildad, generosidad, castidad, caridad, abstinencia, paciencia y piedad. La vara llega hasta las nubes, donde se sitúa un trono vacío flanqueado por dos ángeles, reservado para los bienaventurados, según la creencia medieval en que los ángeles caídos habían dejado libres sus tronos, mismos que serían ocupados posteriormente por los hombres salvos. Del lado derecho del grabado está representado el camino del mal. En un primer plano está un hombre sometido por los pecados, lo que se advierte por la proximidad de dos demonios, uno de ellos montado sobre sus espaldas y el otro, flanqueándolo de su lado izquierdo. También el pecador porta una vara, pero en ella se enroscan siete serpientes, alusivas a los siete pecados capitales. ${ }^{10} \mathrm{El}$ trono vacío en medio de llamas del ángulo inferior derecho simboliza la silla dispuesta para los condenados en el infierno ${ }^{11}$ [fig. 4].

La idea de los dos caminos se mantuvo vigente durante el siglo XVII a través de las hagiografías de santos y venerables, los sermones y la literatura moralizante, como los exempla..$^{12}$ En este tipo de obras el camino del bien se caracterizaba mediante espinas y cruces, porque se concebía accidentado y difícil de transitar porque implicaba soledad, sacrificios, renuncia a los placeres terrenales y mortificaciones, mientras que el del mal se simbolizaba mediante rosas, por ser placentero y fácil de recorrer.

Una variante del tema de los dos caminos la encontramos en el pasaje de la vida de santa Catalina de Siena en el que Jesucristo le dio a escoger entre una corona de oro y una de espinas y donde ella naturalmente optó por la última, por lo que toda su vida tuvo que padecer dolores de cabeza. ${ }^{13}$ Esta historia llegó a ser muy popular en Nueva España, y la santa fue imitada por monjas y beatas que exageraron el uso de disciplinas y mortificaciones para sentirse portadoras de la corona de espinas.

Resulta significativo que no se hayan conservado representaciones pictóricas de los caminos del bien y del mal que daten del siglo XVII, pero el tema reaparece en el siglo XVIII. Esto es similar a lo sucedido con las representaciones gráficas del infierno, que fueron abundantes en el siglo XVI, dejaron de pintarse en el XVII y reaparecieron en el siglo XVIII, en el contexto de una renovada inquietud por la salvación del alma. Ésta fue promovida en gran medida por los jesuitas, y posteriormente por los filipenses, quienes impulsaron la realización de ejercicios espirituales, la mortificación del cuerpo mediante cilicios,

${ }^{10}$ Los siete pecados capitales son: lujuria, gula, avaricia, pereza, ira, envidia y soberbia.

11 VALADÉs 1989: 484 - 485. Elena Estada de Gerlero identifica este trono con la silla de hierro rusiente descrito por Eusebio de Cesarea en: CESAREA 1987: 88.

12 Dehouve 2000; Rubial García 1999.

13 Rubial García 2003: 355-356. 
flagelos, ayunos y desvelos, y difundieron obras teológicas y doctrinales sobre el más allá, y mandaron hacer pinturas de contenido escatológico. El renovado interés por estos asuntos parece que fue una reacción en contra del racionalismo y de la ilustración, así como del relajamiento de las costumbres que acompañó al régimen borbónico. ${ }^{14}$

\section{LA REPRESENTACIÓN DE LOS CAMINOS DEL BIEN Y DEL MAL EN LAS TRES PINTURAS}

Las tres pinturas que nos ocupan tienen como tema central los caminos del bien y del mal, con la salvedad que La caridad perfecta de Jesucristo soberano redentor del mundo de Antonio Sánchez quien además se refiere al papel redentor de Jesucristo. En los tres casos los pintores respetaron el significado simbólico que el cristianismo atribuye a los rumbos del universo, pero, por razones compositivas, no utilizaron la división más común que sitúa el cielo arriba y el infierno abajo, sino que optaron por la diferenciación derecha e izquierda, en la cual la primera corresponde a la salvación y la segunda, a la condenación. Esta connotación simbólica del espacio tiene un origen bíblico y su antecedente formal se encuentra en las representaciones medievales del juicio final, en las que el cielo siempre aparece a la derecha de Jesucristo y el infierno, a la izquierda. ${ }^{15}$ Antonio Sánchez y el pintor de Rey de Jerusalén y rey de Jericó toman como referente a Jesucristo, quien es la figura principal en ambos lienzos, y sitúan al cielo a su derecha, y al infierno a su izquierda (lado izquierdo y derecho del espectador) [figs. 1 y 3], mientras que en Los peligros del alma se toma de referente la posición del espectador y, por lo tanto, el infierno aparece a la izquierda y el cielo a la derecha ${ }^{16}$ [fig. 2].

14 Villavicencio García 2009: 13-15.

15 Véase por ejemplo: Mateo, 25, 34: Entonces el Rey dirá a los de su derecha:Venid, benditos de mi Padre, heredad el reino preparado para vosotros desde la fundación del mundo y 25 , 41: Entonces dirá también a los de la izquierda: Apartaos de mí, malditos, al fuego eterno preparado para el diablo y sus ángeles.

${ }^{16}$ A pesar de la mutilación es seguro que el cielo aparecía a la derecha porque es el rumbo que señala el ángel. 


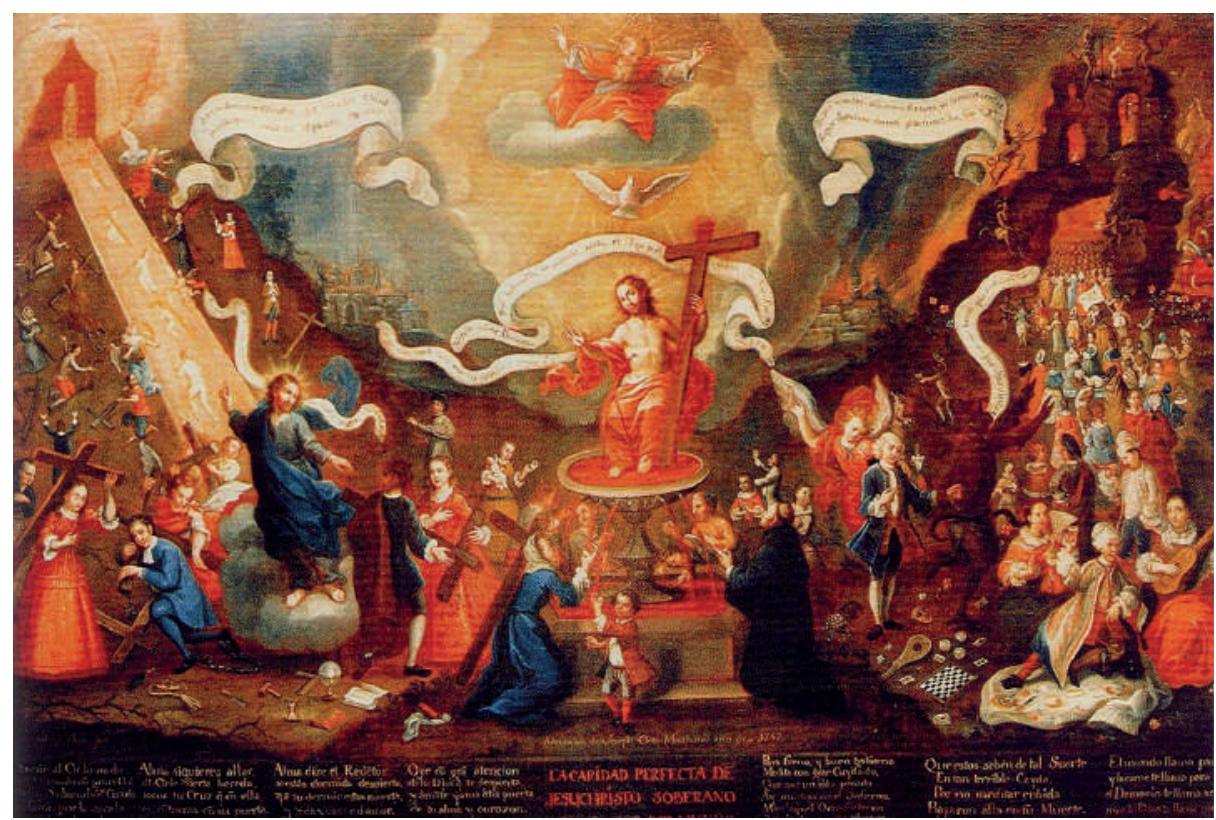

Fig. 1. Antonio Sánchez, La caridad perfecta de Jesucristo soberano redentor del mundo, óleo sobre tela, 1757 (Colección privada).

Durante el Medievo se impuso la idea de que la bienaventuranza estaba reservada para unos cuantos y que, por lo tanto, el camino hacia el cielo era angosto y la puerta de acceso al cielo, estrecha. Esta creencia se basa en afirmaciones bíblicas como la siguiente "es más fácil que un camello entre por el ojo de una aguja que un rico entre en el reino de Dios". ${ }^{17}$ Así, el camino del bien pintado por Antonio Sánchez en La caridad perfecta es angosto y muy empinado y la puerta del cielo es tan estrecha que sólo permite la entrada de una persona a la vez. Además, es extremadamente luminoso ya que evoca la luz celestial que envuelve a la divina Trinidad. Junto al camino hay cruces disponibles para que los fieles se pongan en marcha con ellas.

En contraposición, el camino del mal es espacioso y muy transitado y la puerta de entrada al infierno es amplia y está diseñada para dar acceso a muchas personas. Los tonos que predominan allí son oscuros, principalmente el rojo que simboliza el fuego infernal. (fig. 1) Igualmente, en Los peligros del alma y en Rey de Jerusalén y rey de Jericó son muchas las personas que transitan por el camino del mal. En el primer caso el infierno sólo se insinúa mediante llamas en tonos rojos y amarillos, mientras en el segundo el pintor anónimo utiliza azules y grises [figs. 2 y 3 ].

17 LuCAS 18, 24-30. 


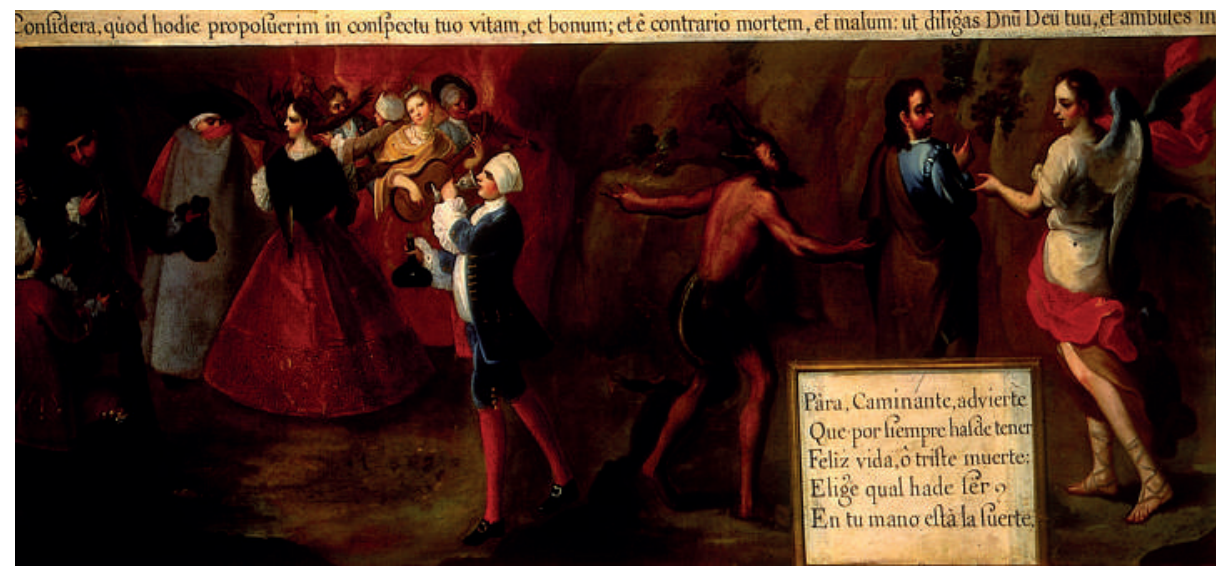

Fig. 2. Anónimo, Los peligros del alma, óleo sobre tela (Colección de la Pinacoteca de la Profesa).

Dios y el Demonio, como figuras supremas del bien y el mal, encabezan los caminos. Antonio Sánchez los coloca al pie de cada uno de ellos, con los brazos derecho e izquierdo extendidos, señalando con el dedo índice al cielo y al infierno, correspondientemente. Mientras Jesucristo es luminoso y está ataviado con manto azul celeste, el Demonio es un oscuro dragón alado [fig. 1]. Por su parte, el pintor anónimo de Los peligros del alma crea un demonio antropozoomorfo, que recuerda al dios griego Pan o a un sátiro, mientras que la figura de Jesucristo está sustituida por el ángel que señala hacia el camino de salvación. Los ángeles se consideraban emisarios de Dios y se creía que tenían la misión de proteger a los fieles y guiarlos por el camino del bien. Existía la creencia de que cada persona al nacer era dotada de un ángel de la guarda para que éste lo protegiera durante toda su vida. El teólogo italiano Pablo Señeri, cuya obra fue ampliamente difundida en Nueva España, lo nombra "guía y escolta de mi peregrinación" 18 [fig. 2].

En Rey de Jerusalén y rey de Jericó Jesucristo y Lucifer aparecen como dos soberanos que abanderan sus caminos. Jesucristo porta una bandera blanca, que alude a la pureza y luminosidad del cielo, marcada con la señal de la cruz, el símbolo de la pasión. El rojo de la bandera de Lucifer se refiere al fuego infernal. Las inscripciones al pie de los personajes dicen Rex Jerusalem y Rex Jericho [rey de Jerusalén y rey de Jericó]. Esta alegoría se basa en las meditaciones número 135 a 145 de los Ejercicios espirituales de San Ignacio de Loyola. ${ }^{19}$

\footnotetext{
18 SEÑERI 1780: 91.

19 Los jesuitas introdujeron en Nueva España la práctica de las meditaciones espirituales, que tuvo gran aceptación y fue muy extendida entre los novohispanos. Éstas se llevaban a cabo
} 
Loyola invita a quienes van a realizar los ejercicios espirituales a concebir a Jesucristo y a Lucifer como dos "caudillos": Cristo, como "sumo y verdadero capitán" que guía a los cristianos hacia la vida eterna en el cielo y Lucifer como "mortal enemigo de nuestra humana natura". Cada caudillo porta una bandera y quiere tener "a todos debajo de [ella]". Como escenario de los hechos propone evocar para Jesucristo y sus seguidores un gran campo en Jerusalén, y para Lucifer otro, en Babilonia. Detalla que este último debía aparecer como una gran catedral de "fuego y humo" y Lucifer, como una "figura horrible y espantosa". Loyola asienta que Lucifer hace un llamamiento a todos los demonios y los esparce por el mundo para tentar a los hombres y convencerlos de que opten por las "riquezas", el "vano honor del mundo" y "la soberbia", mientras Jesucristo hace lo propio con sus discípulos y apóstoles, pero para difundir su "sagrada doctrina" 20 [fig. 3].

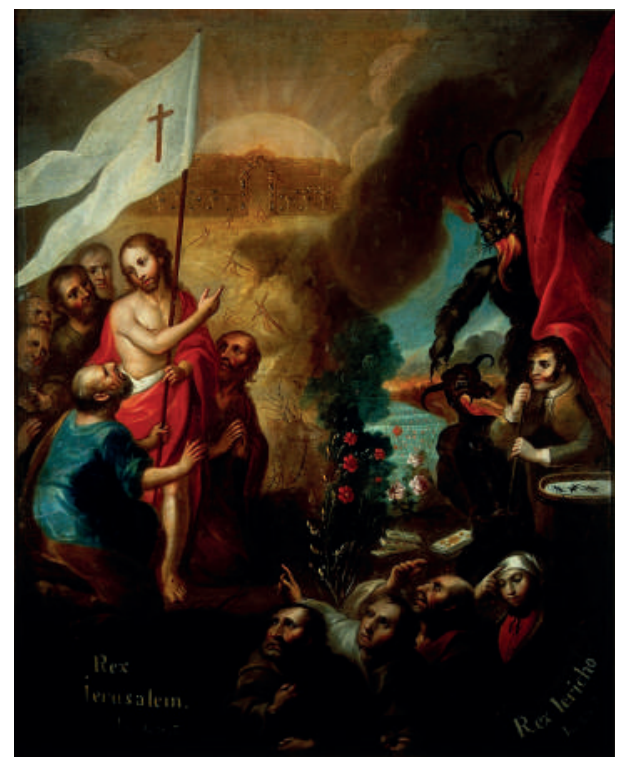

Fig. 3. Francisco Jerónimo Zendejas (atribuido), Rey de Jerusalén y rey de Jericó (conocida comúnmente como Cristo descendiendo al infierno), (Museo Nacional de Historia de la Ciudad de México).

a través de la obra del santo y de otros tratados de gran circulación, véase por ejemplo: RosigNOLI 1764: 293-322.

${ }^{20}$ Loyola 1991: 307-310. 

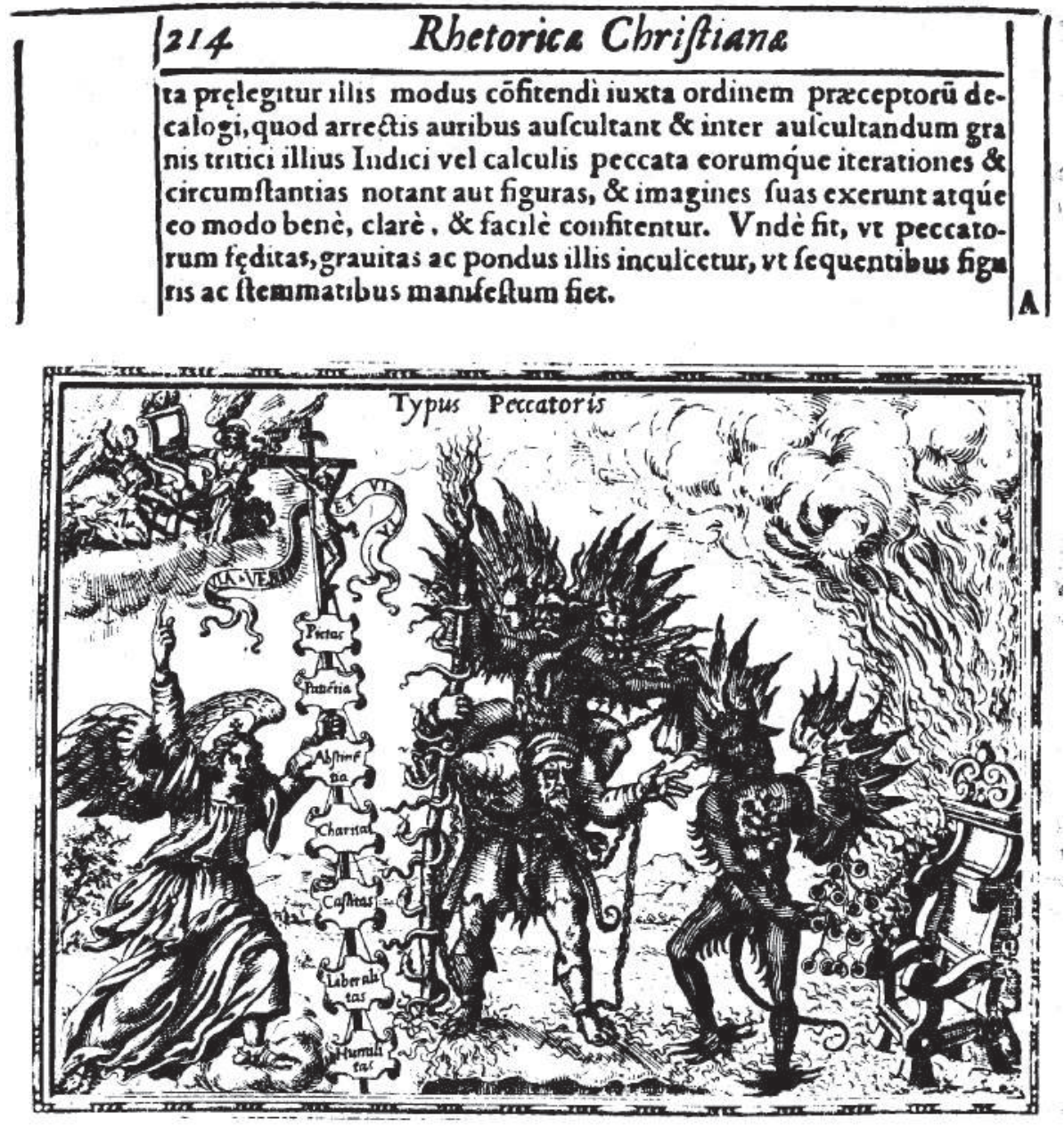

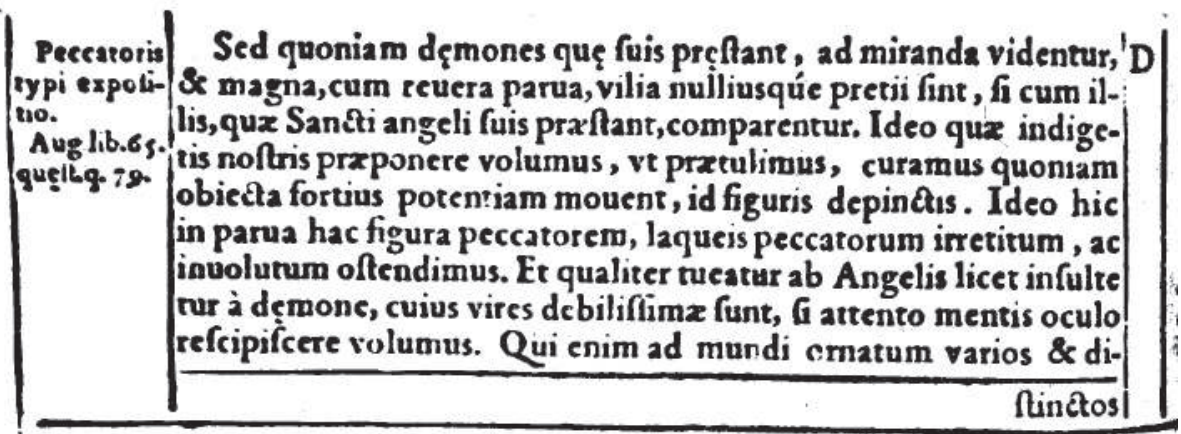

Fig. 4. Diego Valadés, "Representación del pecador”, grabado perteneciente a la obra Retórica cristiana. 
Como se advierte, en lo fundamental hay coincidencia entre la pintura y el mencionado texto y resulta admisible que el pintor haya convertido a los caudillos en reyes, ya que, según la concepción cortesana del más allá, Dios y el Demonio eran considerados reyes o emperadores de sus respectivos reinos. Sin embargo, desconcierta la sustitución del reino de Babilonia por el de Jericó. Esta transposición posiblemente aluda a la conquista de Jericó por los israelitas, descrita en el libro del Antiguo Testamento, y durante la cual Yahvé puso a su rey en manos de Josué, a la vez que declaró anatema la ciudad. ${ }^{21}$ Lo que resulta oscuro es la identidad del personaje masculino, vestido a la moda de finales del siglo XVIII, que ayuda a sostener el estandarte enarbolado por Lucifer. ¿Se trata del rey de Jericó, es algún personaje contemporáneo o es el Anticristo?

Parece intencional de que en esta obra los caminos no están bien delimitados. Mediante la negra nube infernal que se proyecta sobre el camino del bien y obliga a sus caminantes a esquivarla para continuar su marcha hacia el paraíso, el pintor muestra que las trayectorias de vida de los hombres no son lineales. Siempre existe la posibilidad de cambiar de rumbo: la fuerza redentora de Jesucristo hace posible que aún los mayores pecadores puedan regresar a la senda del bien, a la vez que personas virtuosas, en cualquier momento pueden pecar y caer en el camino del mal [fig. 3].

Las otras dos pinturas también aluden a esta fragilidad existencial. En $L a$ caridad perfecta un hombre vestido elegantemente a la francesa, guiado por el Demonio, que lo tiene asido de la mano izquierda, está incursionado en el camino de la perdición mientras que un ángel lo detiene del hombro para convencerlo que regrese al buen camino. En Los peligros del alma aparece una escena parecida. La persona del centro, en un primer plano, es disputada por un ángel y un demonio, pero en este caso ella sigue al ángel y no atiende al demonio [figs. 1 y 2].

La cartela situada al pie de la figura refuerza la idea del libre albedrío:

Para caminante, advierte

que para siempre has de tener

feliz vida o triste muerte

elige cuál ha de ser,

en tus manos está la suerte. [fig. 2]

La idea de que el demonio tienta a los hombres para apartarlos del camino del bien está presente en la obra de muchos teólogos y pensadores novohispanos. El carmelita Agustín de la Madre de Dios, por ejemplo, afirma que el Demonio era el "capital enemigo de nuestro bien" y que siempre estaba "anhelando nuestro mal" y procurando "deshacer la liga de la amistad que une nuestros

21 JosuÉ 6, 13-27. 
corazones con el amor". ${ }^{22}$ Se creía que tenía un empeño especial en recuperar las almas que transitaban por la senda del bien y, por lo tanto, estaban perdidas para el infierno, razón por la cual frailes, monjas, ascetas y beatas se sentían permanentemente expuestos a sus embates. La pintura anónima, Condiciones de una buena confesión, por ejemplo, muestra la confesión de dos personas, en las cuales el Demonio está presente. En la escena representada del lado izquierdo, él se incomoda y manifiesta su descontento al decir "mal he quedado", porque se trata de una persona de vida recta que se ha confesado correctamente $y$, por lo tanto, se encuentra en el camino del bien; mientras tanto, en la confesión representada del lado izquierdo, exclama satisfecho "éste es mío", ya que se trata de un pecador que no se ha confesado correctamente y es candidato al infierno [fig. 5].

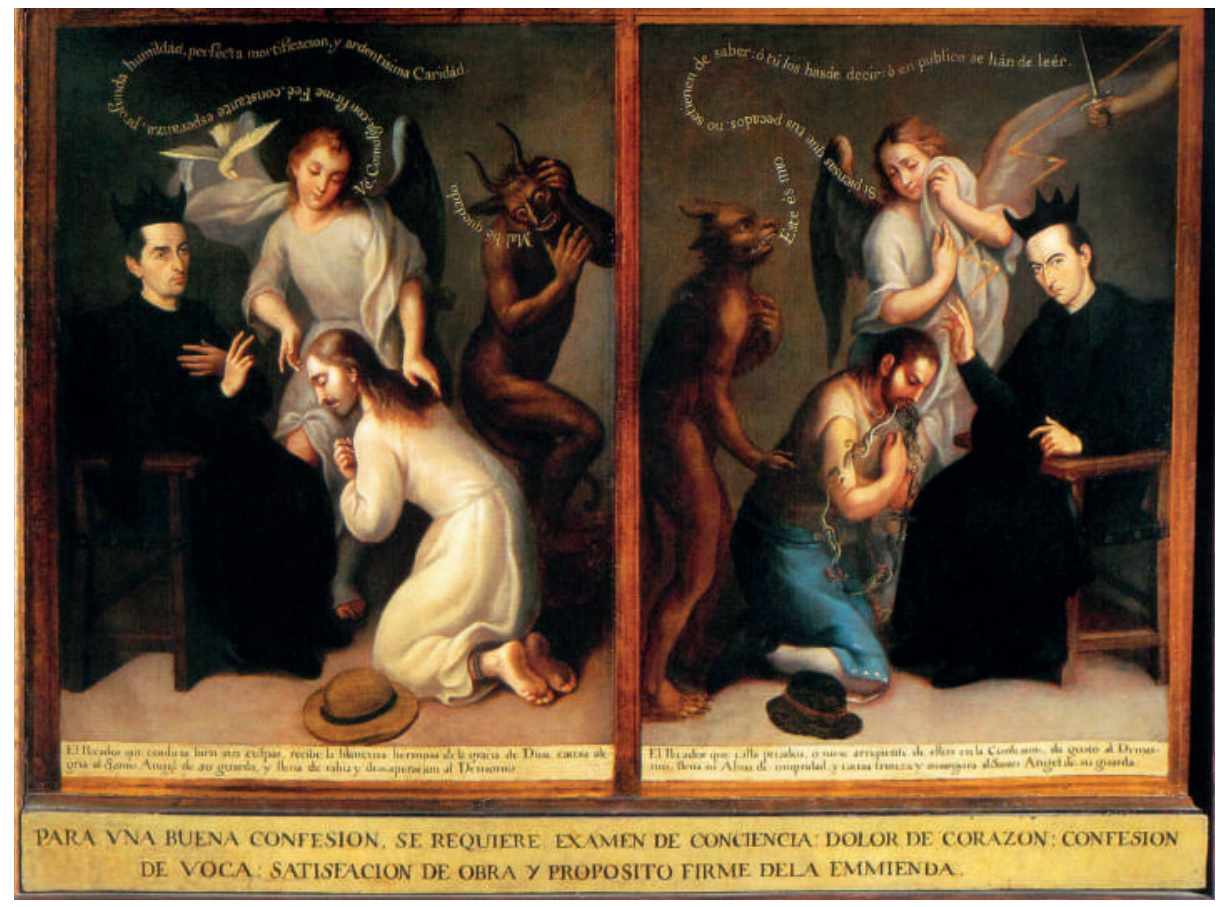

Fig. 5. Anónimo, Condiciones de una buena confesión, Iglesia de San Felipe Neri "La Profesa", México DF.

${ }^{22}$ MAdre De Dios 1984: 214. 
Las historias de la presencia de las huestes demoníacas en los conventos masculinos y femeninos son recurrentes en las crónicas. ${ }^{23}$ Gómez de la Parra se refiere, por ejemplo, a los acosos que sufría la "tierna, virgen y casta doncella" Juana de San Pablo, a los que padeció Isabel de la Encarnación a lo largo de toda su vida, razón por la cual sus contemporáneos la consideraron elegida de Dios, así como a los que soportaron María del Santísimo Sacramento y María del Niño Jesús, todas ellas monjas del convento de carmelitas descalzas de Puebla. ${ }^{24}$

En La caridad perfecta de Jesucristo soberano redentor del mundo una multitud de personas transita por el camino del mal, lo que contrasta flagrantemente con las cinco almas que escalan el sendero del bien y cuyos cuerpos blancos denotan que ya están a salvo y pronto formarán parte de los bienaventurados. El pintor anónimo de Los peligros del alma limitó el número de seres que se encaminan al infierno a diez y podemos suponer que el grupo de los que iban por la senda de la salvación debe haber sido mucho más restringido, tal vez se trataba sólo de una o dos personas [figs. 1 y 2].

En el Rey de Jerusalén y rey de Jericó, Cristo está rodeado de sus discípulos. Cinco personas que cargan cruces se dirigen hacia la puerta de la Nueva Jerusalén, mientras que Lucifer sólo parece tener seguro a un adepto, el personaje de identidad dudosa que se cobija bajo su bandera colorada. El mensaje de esta pintura sobre los que se salvan y los que se condenan difiere de las otras dos, dado que el pensamiento ignaciano es más incluyente y ofrece la posibilidad de salvación para todos sus seguidores; Loyola pone en boca de Jesucristo las siguientes palabras: "Mi voluntad es de conquistar todo el mundo y todos los enemigos y así entrar en la gloria de mi Padre; por tanto quien quisiere venir conmigo ha de trabajar conmigo, porque siguiéndome en la pena, también me siga en la gloria." 25 [fig. 3].

\section{Placeres y diversiones en el CAMino del Mal, TRABAJOS Y SUFRIMIENTO EN EL DEL BIEN}

La Iglesia proponía una serie de actividades y comportamientos antagónicos para los dos caminos, correspondientes a las virtudes y a los vicios. Había una aceptación explícita de que practicar las virtudes era difícil, porque implicaba trabajos y sufrimiento, y por el contrario, caer en los vicios era fácil, por ser

${ }^{23}$ Véase, por ejemplo, la presencia de las huestes demoníacas en el convento de carmelitas descalzas en Puebla. Gómez de la PARra 1992: 150.

${ }^{24}$ Gómez de la Parra 1992: 150, 174, 213 y 157.

${ }^{25}$ Loyola 1991: 218. 
placenteros. Así, metafóricamente el camino del bien se concebía sembrado de espinas, mientras que el del mal, de rosas. Tanto Sánchez como el pintor anónimo de Rey de Jerusalén y rey de Jericó incorporaron estos símbolos en sus obras [figs. 1 y 3 ].

Los atractivos del camino del mal, que atraían a muchas personas pertenecían a cuatro categorías: bienes materiales, entre ellos trajes lujosos y joyas; placeres sensoriales relacionados con los cinco sentidos; diversiones mundanas, como tertulias, paseos, funciones de teatro y conversaciones con amigos, y, por último, honores y glorias terrenales, entre ellos cargos públicos y distinciones. ${ }^{26}$

Para representar estos bienes y placeres los pintores recurrieron a los símbolos utilizados en las pinturas de vanitas, que surgieron en la Edad Media, que exhibían lo efímero y fugaz de las cosas terrenales, tales como el dinero, los lujos y la belleza.

De las tres obras analizadas, la más rica en estos símbolos es La caridad perfecta. Allí aparecen, en primer plano, numerosas personas divirtiéndose y gozando de la buena vida. Sus ricos vestidos hacen alarde de buen gusto y contrastan con la sencilla indumentaria que portan los aspirantes al cielo. El personaje atrapado por el Demonio, que está a punto de abordar el camino del mal, por ejemplo, está vestido a la francesa, con peluca de rizos blancos, medias, pantalón corto y casaca. Las mujeres y el hombre que se encuentran en primer plano en el extremo inferior derecho asimismo están ataviados opulentamente: él con turbante, capa de seda, medias, chaleco y pantalón corto y ellas con blusas de olanes, flores en el pelo, abanicos y amplias faldas largas. Otras personas portan capas, sombreros y tricornios [fig. 1].

Lo mismo se repite en Los peligros del alma donde el personaje masculino del centro en primer plano porta un elegante traje estilo francés, con medias rojas, pantalón y casaca azules, camisa con holanes y turbante. Una dama que va del brazo de un hombre con disfraz trae una amplia falda roja, con encaje o bordado en la parte inferior y una capa sobre una blusa blanca y un antifaz. El resto de las personas asimismo viste lujosamente [fig. 2].

Entre los placeres sensoriales que hacían peligrar el alma figuran la comida y bebida, especialmente el alcohol, cuyo disfrute implicaba los pecados de la gula y la intemperancia. En La caridad perfecta encontramos en primer plano un banquete, que disfrutan dos mujeres y un hombre. Sobre un mantel desplegado en el piso están dispuestos distintos platillos, así como dos botellas de vino y el hombre lleva una copa en su mano [fig. 1]. En Los peligros del alma el caballero del primer plano trae una garrafa de vino en las manos, a la vez que

26 Tomado DE: Bolaños 1992: 261-262. 
se empina una copa del mismo líquido [fig. 2]. En La caridad perfecta vemos en un segundo plano a un hombre de perfil fumando pipa [fig. 1]. Fumar era considerado vicio y se asociaba a la mala vida, véase por ejemplo la cigarrera que cuelga del brazo de la prostituta en San Juan de Dios muestra el camino de la salvación a cuatro prostitutas de la ciudad de Granada de Luis Berrueco.

Los placeres auditivos, particularmente la música profana, eran considerados riesgosos para el alma. Los instrumentos de cuerdas que se aprecian en $\mathrm{La}$ caridad perfecta y en Los peligros del alma, laúdes, vihuelas y un violín aluden a la música profana a la vez que simbolizan lo transitorio de los placeres terrenales. ${ }^{27}$ Otras actividades del camino del mal eran la danza y el teatro, representadas por Sánchez mediante una máscara, y por el pintor anónimo de Los peligros del alma por un hombre y una mujer con antifaces, que tomados del brazo avanzan al son de la música [figs.1 y 2].

Los juegos de azar simbolizaban por excelencia lo peligroso y efímero de los placeres terrenales. Este es el significado de los naipes que incluye el pintor de Rey de Jerusalén y rey de Jericó en la sección correspondiente al infierno. También Sánchez les da un lugar preponderante al mostrar, en primer plano, un tablero de ajedrez, naipes y pelotas. Juegos tales como dados y naipes no sólo los prohibía la Iglesia sino también la Corona, ${ }^{28}$ pero a pesar de ello había gran afición al juego y representaba un buen ingreso fiscal, dado los elevados impuestos que se pagaban sobre él [fig. 3].

El dinero, distintivo de riqueza, conducía a los pecados de la avaricia y la usura. Sánchez coloca una bolsa abierta en el piso, junto a los naipes, de la cual se desparraman varias monedas de plata. El pintor de Los peligros del alma representa, en un primer plano, a un personaje masculino que exhibe otra bolsa de dinero, a la par que charla con dos camaradas. La posesión de dinero se asociaba a los pecados de la avaricia y la usura. Dado que en aquella época se consideraba usura cualquier ganancia sobre el capital, todas las personas que tenían un estatus económico elevado estaban en riesgo de haber cometido este pecado, considerado uno de los más severos en los que podía incurrir una persona ${ }^{29}$ [figs. 1, 2 y 3].

La representación de los placeres carnales resulta poco evidente para nuestra mirada contemporánea, acostumbrada a escenas de erotismo franco. Sin embargo, un observador acucioso podrá advertir el contacto físico existente en la pareja del primer plano del óleo de Sánchez y entre los danzantes en Los peligros del alma, es poco frecuente en la pintura de la época, si se exceptúan las escenas galantes, y que sin duda apunta hacia los placeres sexuales [figs. 1 y 2].

${ }^{27}$ BATTISTINI 2003: 361.

${ }^{28}$ Véase Leyes de Indias, libro 7, título 2.

29 VON WOBESER 1993: 121-145. 
Debido a que la principal intención de las pinturas sobre los caminos era alejar a las personas de los vicios, la representación de las virtudes es mucho menos detallada y, como ya se había señalado, en Los peligros del alma falta del todo por la mutilación de la tela [fig. 2]. La pintura Rey de Jerusalén y rey de Jericó sólo muestra las cruces que portan las cinco personas que ascienden hacia la Nueva Jerusalén [fig. 3].

Una vez más es la obra de Sánchez la que aporta la mayor riqueza simbólica. El primer elemento virtuoso se encuentra en los trajes que portan las personas que están al pie del camino del bien, así como las que transitan por el mismo. Se trata de ropa austera, carente de lujos y que contrasta con la que exhiben los personajes del camino de la perdición. Al pie del camino del bien se encuentran objetos alusivos al trabajo, a las mortificaciones del cuerpo y al culto religioso. Entre los primeros destaca un costurero, un martillo, una regla en escuadra y algo que parece ser un cincel. El flagelo y el cilicio simbolizan las prácticas ascéticas que la Iglesia proponía como medio de salvación y cuyo uso estaba muy extendido en los conventos y también, en menor proporción, en el resto de la población. Fray Agustín de la Madre de Dios, por ejemplo, pondera la vida ascética de fray Mateo de Ortigoza de la siguiente manera: "ayunaba muchas veces a pan y agua; tomaba cada noche una disciplina, y muchas tardes se iba disimulado a los hospitales, en especial de los indios, donde con suma humildad les limpiaba y servía, dejándoles de camino lo que podía adquirir para consuelo y regalo. Otras veces, iba a pie a visitar las milagrosísimas imágenes de los Remedios y de Guadalupe, donde se estaba todo el día sin comer, en un rincón de la iglesia, hincado de rodillas. ${ }^{30}$

Entre los objetos religiosos destacan dos libros, probablemente un misal y un catecismo, así como una custodia. Estos objetos aluden a los rezos, a la asistencia a misa, a la comunión, al recogimiento y a la íntima comunicación con Dios.

\section{LA AMBIVALENCIA EN LA UTILIZACIÓN DE LOS SíMbOLOS}

Los símbolos utilizados por los pintores para transmitir los mensajes moralistas contenidos en las obras descritas no tienen un significado unívoco, ya que éste varía de acuerdo con el contexto en el que aparecen en distintas obras pictóricas o literarias. Por ejemplo, las rosas no siempre se asocian al mal, sino por el contrario representan el bien cuando forman parte de la iconografía del paraíso; son atributos de la Virgen o santas, como santa Rosa de Lima, que porta una

\footnotetext{
30 VON WOBESER 1993: 198.
} 
corona de dichas flores en la cabeza; o cuando simbolizan las virtudes, como en el caso de algunas de las visiones místicas que tuvo Catarina de San Juan según la biografía hagiográfica de Alonso Ramos: „En otras ocasiones [Catarina] veía bajar del cielo sus oraciones transformadas en fragantes flores y purpúreas rosas que matizaban y poblaban el suelo, simbolizando el deleitoso jardín de virtudes que adornaban su dichosa alma o los descansos eternos de la gloria con que la alentaba el Esposo, como a la otra alma santa, a quien dijo: Mira nuestra patria feliz, qué enriquecida está de flores y rosas, y la voz de la tórtola se ha oído en nuestra tierra." 31

Tampoco las espinas siempre significaron el bien. El propio Alonso Ramos, por ejemplo, usa la metáfora de "las espinas del gentilismo" para referirse a los pueblos del norte de la India que no estaban cristianizados. ${ }^{32}$ Los flagelos que en la obra de Sánchez simbolizan la mortificación del cuerpo y el control de las pasiones de la carne y que forman parte de la vida ascética que la Iglesia prescribía a los fieles que querían alcanzar la gloria, adquieren otro significado en las representaciones en las que los soldados romanos azotan a Jesucristo durante la pasión y aluden al mal trato que éste recibió de los judíos.

La vestimenta suntuosa y las joyas no significan elementos de vanitas cuando se trata de retratos de la nobleza o de personajes celestiales. Éstos últimos con frecuencia son imaginados con ricos atavíos, acordes a la idea señorial del cielo, que provenía de su identificación con la Jerusalén celestial. Por ejemplo, el pintor que firma Cháves dignificó el sencillo hábito carmelita de la Virgen del Carmen al colocarle adornos y ribetes dorados y dotarlo de una capa, igualmente con aplicaciones doradas. Agustín de la Madre de Dios describe una procesión de ángeles que acompañó a fray Francisco de los Reyes durante su ingreso triunfal al cielo. El fraile llevaba su hábito de carmelita, pero ya no era el sencillo y desgastado que solía usar, sino que éste era "de tela preciosísima" y además tenía una capa, ambos "bordados de gran primor." 33

Los instrumentos de música que en las pinturas analizadas simbolizan diversiones y entretenimientos mundanos, tienen un significado opuesto cuando se trata de música sacra o celestial. En las representaciones del cielo los ángeles músicos son una de las expresiones más elevadas de la adoración a Dios y se asocian con la visión beatífica. Así aparecen en María reina de los ángeles de Blas de Torres y en El martirio de santa Margarita de Cristóbal de Villalpando, para citar sólo dos ejemplos. La ya mencionada Sebastiana de las Vírgenes describe a los coros celestiales de la siguiente manera: "Iban con dulces

\footnotetext{
31 Ramos 2004: v.1, f. 66.

32 Ramos 2004: v.1, f. 32.

33 Madre De Dios 1984: 167.
} 
voces y acordados instrumentos cantando himnos de alabanzas a Dios y a la Soberana Reina". ${ }^{34}$

Los naipes y demás juegos, el dinero, el tabaco, las licoreras y el baile, y la música profana tienen un significado simbólico más permanente como objetos perniciosos para la salvación del alma. Sin embargo, en la pintura costumbrista del siglo XVIII, dentro del género de la "pintura de castas" hay escenas donde estos objetos no parecen expresar malos comportamientos sino más bien reflejar las actividades comunes de la población. Un ejemplo es la partida de cartas que juegan un español, su esposa india y la hija mestiza en la obra De español e india nace mestiza de Buenaventura José Guiol, que data de c. 1770-1780. ${ }^{35}$

\section{COMENTARios FinALES}

Para finalizar cabe reflexionar sobre el impacto que estas pinturas, así como los textos moralistas, tuvieron sobre los receptores. Sin duda, hubo muchas personas que trataron de apegarse lo más posible a este ideal de vida propagado por la Iglesia. De ellas tenemos noticias a través de hagiografías, crónicas conventuales y procesos inquisitoriales en contra de santos espontáneos, místicos y anacoretas. Muchos fueron clérigos como Felipe Neri Alfaro, el fundador del Santuario de Atotonilco, quien llevó una vida extremadamente ascética, y fray Antonio Margil de Jesús, propuesto como venerable a la Sagrada Comisión de Ritos del Vaticano para su eventual beatificación. ${ }^{36}$ Entre las mujeres, un porcentaje elevado corresponde a monjas, que renunciaron a los placeres terrenales y mortificaron sus cuerpos, como la queretana María Ignacia del Niño Jesús, una visionaria y mística que dejó testimonio de sus vivencias a través de las cartas dirigidas a su confesor el fraile franciscano Manuel Sancho del Valle y la visionaria concepcionista Sebastiana de las Vírgenes. ${ }^{37}$ También hubo numerosos legos que optaron por el camino de espinas, como Francisco Lerín, un rico comerciante que vendió todos sus bienes para dedicarse como ermitaño a la construcción del santuario de la Virgen de la Salud en Pátzcuaro; la beata carmelita María Josefa de la Peña, quien tuvo la reputación de santa entre sus contemporáneos, y la ilusa Ana Rodríguez de Castro y Arámburu. ${ }^{38}$

Pero, ¿qué pasaba con los demás novohispanos? Los reiterados autos acordados, decretos pastorales y edictos de la inquisición y las reglamentaciones,

\footnotetext{
${ }^{34}$ EsPejo 1995: 208.

35 Katzew 2004: 28.

36 Santiago Silva 2004; Rubial García 2000: 29, Rubial García 1999: 251-295.

37 GunNARSDOTTIR 2002: 364-383; EsPEJo 1995.

38 JAFFARY 2006: 94-133; BRAVO 1984.
} 
reales cédulas sobre la relajación de las costumbres, que aparecieron sobre todo a partir de la quinta década del siglo XVII y durante el siglo XVIII, parecen indicar que para la mayor parte de la población los preceptos eclesiásticos permanecieron como una meta inalcanzable. ${ }^{39}$ Incluso muchos clérigos, especialmente los seculares, vivían en gran libertinaje y asistían a prostíbulos, bailes y casas de juego. Asimismo, era tolerado que los clérigos tuvieran mujeres e hijos y el pecado de solicitación, es decir, el acoso a mujeres durante la confesión era muy común, aunque penado por la Iglesia. Incluso entre los carmelitas descalzos, cuyas reglas eran muy austeras, había adictos al juego y a las mujeres, entre otras faltas de indisciplina. ${ }^{40}$

Por otra parte, en el siglo XVIII, el alcohol y el tabaco eran consumidos por un porcentaje elevado de la población. Entre 1795 y 1799, el primero redituaba a la tesorería un promedio de 808,732 pesos al año, lo que significaba cerca del $4 \%$ del total de las recaudaciones, y el segundo, 7,540,617 pesos, el 36\% del total de ingresos estatales, lo que se explica por el monopolio que el Estado ejercía sobre el tabaco. También los naipes eran monopolio y dejaban buenas ganancias; aportaban en promedio 172,146 pesos, el $0.84 \%$ de las recaudaciones totales.$^{41}$ Eran comunes las corridas de toros, peleas de gallos y el teatro de entretenimiento y las fiestas callejeras tuvieron un gran auge. ${ }^{42}$ Finalmente, el honor constituyó una de las mayores aspiraciones de las personas de los estratos altos de la sociedad, que se materializaba en los cargos civiles y religiosos importantes, títulos de nobleza, mayorazgos, así como todo tipo de merecimientos de acuerdo con el estatus de cada persona.

\section{Bibliografía}

Battistini 2003 - M. Battistini, Símbolos y alegorías, trad. de J.R. Monreal, Barcelona, Electra, 2003.

Bolaños 1992 - J. Bolaños, La portentosa vida de la muerte, edición crítica, introducción y notas de Blanca López de Mariscal, México, El Colegio de México, 1992.

Bravo 1984 - D. Bravo,(ed.) Ana Rodríguez de Castro y Aramburu, ilusa, afectadora de santos, falsos milagros y revelaciones divinas. Proceso Inquisitorial en la Nueva España. Trascripción de A. Herrera, México,

\footnotetext{
39 Viqueira Alban 1987: 18.

40 Ramos Medina 2008: 241-243.

${ }^{41}$ MARICHAL 1999: 308-309.

42 Marichal 1999: 308; Viqueira Alban 1987, cap. 1-3.
} 
Secretaría de Educación Pública, Instituto Nacional de Bellas Artes y Universidad Autónoma Metropolitana, 1984.

Cesarea 1987 - E. de Cesarea. "La demonología en la obra gráfica de fray Diego Valadés", en: Iconología y sociedad. Arte colonial hispanoamericano. Memorias del XLIV Congreso Internacional de Americanistas, México, Universidad Nacional Autónoma de México, 1987.

Curiel y Rubial 1999 - G. Curiel y A. Rubial, "Los espejos de lo propio: ritos públicos y usos privados en la pintura virreinal". En: G. Curiel et al., Pintura y vida cotidiana en México, 1650-1950, México, Fomento Cultural Banamex y Conaculta, 1999.

Dehouve 2000 - D. Dehouve, Rudingero el borracho y otros exempla medievales en el México virreinal, México, Miguel Ángel Porrúa, Universidad Iberoamericana y Ciesas, 2000.

EsPEJo 1995 - B. Espejo, En religiosos incendios, México, Universidad Nacional Autónoma de México, 1995.

Gómez de la PARRa 1992 - J. Gómez de la Parra, Fundación y primer siglo. Crónica del primer convento de carmelitas descalzas en Puebla. 1604-1704, M. Ramos Medina (introd.), México, Universidad Iberoamericana y Comisión Puebla Quinto Centenario, 1992.

GunNarSDotTIR 2002 - E. Gunnarsdottir, „Cartas de Francisca de los Ángeles de 1693 a 1727", en: Monjas y beatas. La escritura femenina en la espiritualidad barroca novohispana. Siglos XVII y XVIII, A. Lavrin y Rosalva Loreto L. (eds.), México, Universidad de las Américas y Archivo General de la Nación, 2002, pp. 364-383.

JAFFARY 2006 - N.E. Jaffary, "María Josefa de la Peña y la defensa de la legitimidad mística", en: Diálogos espirituales. Manuscritos femeninos hispanoamericanos, Siglos XVI-XIX, A. Lavrin y Rosalva Loreto L. (eds.), Puebla, Benemérita Universidad de Puebla y Universidad de las Américas, 2006, pp. 94-133

KATZEW 2004 - I. Katzew, La pintura de castas. Representaciones raciales en el México del siglo XVIII, México, Conaculta Turner, 2004.

Loyola 1991 - I. de Loyola, Ejercicios espirituales, en: S.S.J. Arzubialde, Ejercicios espirituales de S. Ignacio, Historia y análisis, Bilbao-Santander, Mensajero y Sal Terrae, 1991.

MAdre De Dios 1984 - A. de la Madre de Dios, Tesoro escondido en el Santo Carmelo mexicano. Mina rica de ejemplos y virtudes en la historia de los carmelitas descalzos de la provincia de la Nueva España, M. Ramos Medina, (ed.), México, Probursa e Universidad Iberoamericana, 1984. 
MARICHAL 1999 - C. Marichal, La bancarrota del virreinato. Nueva España y las finanzas del Imperio español, 1780-1810, México, Fondo de Cultura Económica, 1999.

MÉndez 1993 - J.B. Méndez, Crónica de la provincia de Santiago de México de la orden de predicadores (1541-1564), México, Editorial Porrúa, 1993.

Ramos 2004 - A. Ramos, Prodigios de la omnipotencia y milagros de la gracia en la vida de la venerable sierva de Dios Catharina de San Joan, México, Centro de Estudios de Historia CONDUMEX - Sociedad Mexicana de Bibliófilos A.C., 2004.

Ramos Medina 2008 - M. Ramos Medina, El Carmelo novohispano, México, Centro de Estudios de Historia de México Carso, 2008.

Rosignoli 1746 - C.G. Rosignoli Verdades eternas, explicadas en lecciones ordinarias principalmente para los días de los ejercicios espirituales, Madrid, Imprenta de Gabriel Ramírez, 1764.

Rubial GARCíA 1999 - A. Rubial García, La santidad controvertida. Hagiografía y conciencia criolla alrededor de los venerables no canonizados de Nueva España, México, Universidad Nacional Autónoma de México y Fondo de Cultura Económica, 1999.

Rubial García 2000 - A. Rubial García, Profetisas y solitarios. Espacios y mensajes de una religión dirigida por ermitaños y beatas laicos en las ciudades de Nueva España, México, Fondo de Cultura Económica, 2000.

Rubial García 2003 - A. Rubial García, „El hábito de los santos. Construcción y recepción de la santidad de los laicos en la Nueva España del siglo XVII", en: Camino a la santidad, siglos XVI-XX, M. Ramos Medina, (coord.), México, Centro de Estudios de Historia de México CONDUMEX, 2003.

Santiago Silva 2004 - J. de Santiago Silva, Atotonilco. Alfaro y Pocasangre, Guanajuato, Ediciones la Rana, 2004.

SEÑERI 1780 - P. Señeri, El infierno abierto al cristiano, para que no caiga en él o consideraciones de las penas que allá se padecen, Puebla de los Ángeles, Pedro de la Rosa impresor, 1780.

VALADÉs 1989 - D. Valadés, Retórica cristiana, México, Universidad Nacional Autónoma de México y Fondo de Cultura Económica, 1989.

VillaVicencio García 2009 - A.C. Villavicencio García, El infierno abierto al novohispano. Las penas del infierno en el contexto de la pintura escatológica novohispana, Tesis para optar por el grado de maestro en Historia por la Facultad de Filosofía y Letras de la UNAM, 2009. 
Viqueira Alban 1987 - J.P. Viqueira Alban, “¿Relajados o reprimidos? Diversiones públicas y vida social en la ciudad de México durante el Siglo de las Luces, México, Fondo de Cultura Económica, 1987.

VON WobeSER (en prensa) - G. von Wobeser, Cielo, infierno y purgatorio. Representaciones sobre el más allá en Nueva España, Editorial Jus, (en prensa).

VON WoBESER 1993 - G. von Wobeser, „La postura de la iglesia católica frente a la usura", Memorias de la Academia Mexicana de la Historia, vol. 36, 1993, pp. 121-145.

\section{Summary}

\section{The paths of good and evil in the 18th-century painting of the New Spain}

The Catholic Church propagated the idea of the existence of two paths, that of good and that of evil, through images, so that the faithful would regulate their conduct based on the teaching they contained. The path of good, which was ethically recommended, led to heaven. It was called "the path of thorns" because it was of renouncing earthly goods and satisfactions in favour of suffering. The path of evil, presided by the demon, led to hell. It was called "the path of roses" because it was pleasant. In him amusements prevailed, the good life and the enjoyment of sensory pleasures.

Keywords: Colonial painting, New Spain, 18th century, religious iconography

\section{Streszczenie}

\section{Ścieżka dobra i zła w malarstwie nowohiszpańskim w XVIII wieku}

Kościół katolicki poprzez obrazy propagował ideę istnienia dwóch ścieżek, dobra i zła, tak aby wierni mogli kształtować swoje postępowanie na podstawie zawartego w nich nauczania. Droga dobra, która była polecana pod względem etycznym, prowadziła do nieba. Nazywano ją ,ścieżką cierni”, ponieważ oznaczała wyrzeczenie się ziemskich dóbr i satysfakcji i oddanie się cierpieniom. Ścieżka zła, której przewodniczył demon, prowadziła do piekła. Nazywano ją „ścieżką róż”, ponieważ była przyjemna. Panowały na niej rozrywki, radosne życie i cieszenie się zmysłowymi przyjemnościami.

Słowa kluczowe: malarstwo kolonialne, Nowa Hiszpania, XVIII w., ikonografia religijna 